\title{
Assessment of earthquake-induced slope deformation of earth dams using soft computing techniques
}

\author{
Hamed Javdanian ${ }^{\mathrm{a}}$ and Biswajeet Pradhan ${ }^{\mathrm{b}, \mathrm{c} *}$ \\ ${ }^{a}$ Department of Civil Engineering, Shahrekord University, Shahrekord, Iran; \\ Email: javdanian@sku.ac.ir \\ ${ }^{b}$ Centre for Advanced Modelling and Geospatial Information Systems (CAMGIS), Faculty of Engineering \& \\ IT, University of Technology Sydney, 2007 NSW, Australia \\ ${ }^{c}$ Department of Energy and Mineral Resources Engineering, Choongmu-gwan, Sejong University, 209 \\ Neungdong-ro Gwangjin-gu, 05006, Seoul, South Korea \\ Email.Biswajeet24@gmail.com or Biswajeet.Pradhan@uts.edu.au
}

\begin{abstract}
Evaluating behavior of earth dams under dynamic loads is one of the most important problems associated with the initial design of such massive structures. This study focuses on prediction of deformation of earth dams due to earthquake shaking. A total number of 103 real cases of deformation in earth dams due to earthquakes that has occurred over the past years were gathered and analyzed. Using soft computing methods, including feed-forward back-propagation and radial basis function based neural networks; two models were developed to predict slope deformations in earth dams under variant earthquake shaking. Earthquake magnitude $\left(M_{w}\right)$, yield acceleration ratio $\left(a_{y} / a_{\max }\right)$, and fundamental period ratio $\left(T_{d} / T_{p}\right)$ were considered as the most important factors contributing to the level of deformation in earth dams. Subsequently, a sensitivity analysis was conducted to assess the performance of proposed model under various conditions. Finally, the accuracy of the developed soft computing model was compared with the conventional relationships and models to estimate seismic deformations of earth dams. The results demonstrate
\end{abstract}


that the developed neural model can provide accurate predictions in comparison to the available practical charts and recommendations.

Keywords: Earthquake; Earth dam; Slope deformation; ANN; RBF.

\section{Introduction}

It is highly crucial to study the behavior of dams under seismic loading. Inaccurate assessment of the behavior of dams under earthquake shaking could lead to catastrophic damages. Newmark (1965) proposed a sliding block model as the first technique to calculate permanent slope deformations. This simple technique was adopted to estimate the slope deformations under earthquake loading. In the sliding block method, the slide mass was assumed as a rigid block. Meanwhile, the input acceleration (e.g. caused by the earthquake) beyond the yield acceleration, moves the sliding block (Meehan and Vahedifard 2013; Jafarian and Lashgari 2016, 2017).

Some researchers have investigated and modified the sliding block model (Rathje and Bray 2000, Kramer and Smith 1997). In an earlier paper, Makdisi and Seed (1978) modified the sliding block model and included the acceleration of the slide mass response as input acceleration. Then, they adopted the input acceleration to calculate the extent of displacements. Strenk and Wartman (2011) examined the uncertainty of results obtained from the sliding block model in comparison to real cases. Furthermore, a few researchers explored the level of deformation in Earth slopes through numerical approaches such as finite difference (e.g., Kramer and Smith 1997) and finite element (Prevost et al. 1985) methods. In separate papers, Sarma (1975) and Yegian et al. (1991) included the parameters of strong ground motion to evaluate the slope deformation of Earth dams. HynesGriffin and Franklin (1984) did not include the vertical component of earthquake acceleration in 
their calculations. In fact, they estimated the level of deformation in earth dams based on the ratio of slope failure acceleration to maximum earthquake acceleration.

Earthquake-related problems are complex (Ishihara 1996; Jafarian et al. 2018a, b; Javdanian and Jafarian 2018). On the other hand, the behavior of large earth structures such as earth dams are affected by many factors such as fundamental period of dam, settlement characteristics and nonhomogeneity (Rampello et al. 2009). Establishing accurate relationships between such factors poses a serious challenge for geotechnical engineers (Bray and Travasarou 2007; Siyahi and Arslan 2008; Javdanian et al. 2018a,b). These indicate that the advanced computational techniques should be employed to accurately assess the deformation in earth dams due to earthquake shaking. In recent years, soft computing methods (Javdanian et al. 2015b; Najafzadeh et al. 2013, Najafzadeh and Lim 2015) have been successfully used to solve complex problems and handle many geotechnical engineering analyses, such as seismic liquefaction potential of geomaterials (Javdanian 2017a; Hanna et al. 2007; Baziar and Jafarian 2007), dynamic behavior of soils (Javdanian 2017b; Javdanian et al. 2015a,b; Jafarian et al. 2014), lateral ground surface deformations (Javdanian and Mirkamali 2016), landslides analysis (Pradhan and Lee 2010a, b; Pham et al. 2016; Bui et al. 2016, 2017; Kalantar et al. 2018), soil stabilization (Javdanian et al. 2012; Javdanian 2017c; Javdanian and Lee 2018), shear wave velocity of soils (Ghorbani et al. 2012), and forecasting earthquake magnitude (Adeli and Panakkat 2009).

Review of the aforementioned published papers clearly indicates that the studies on earthquakeinduced slope deformation of earth dam based on real cases are rarely found in the literature. This indicates that further studies are needed to address this important issue using robust computational intelligence methods. This study intended to predict the behavior of earth dams under earthquakeinduced vibrations. Comprehensive database of slope deformations of earth dams due to 
earthquake shaking in various region of the world were collected and analyzed. Intelligent neural networks were employed to develop models evaluating the level of seismic deformation of earth dams. Then, sensitivity analysis was carried out on the models. Finally, the performance of the developed soft computing model was compared with the available recommendations for evaluating slope deformation of earth dams.

\section{Earth dam: case studies}

Wide-ranging database of slope deformations of embankments and earth dams due to past earthquake loading in different parts of the world were gathered. These results refer to homogeneous and non-homogeneous earth dams, embankment dams with concrete facing, rockfill dams and a few natural slopes. The collection covers dams whose behaviors were fully documented after well-recorded earthquakes (Abdel-Ghaffar and Scott 1979; Arrau et al. 1985;

Choggang 1988; De Alba et al. 1988; Elgamal et al. 1990; Bardet and Davis 1996; Krinitzsky and Hynes 2002; EERI 2004). The collected data contain 103 real cases. Figs. 1(a-d) show the frequency distribution of earthquake magnitude $\left(M_{w}\right)$, yield acceleration ratio $\left(a_{y} / a_{\max }\right)$, fundamental period ratio $\left(T_{d} / T_{p}\right)$, and value of slope deformation $\left(D_{a v e}\right)$ for the collected results. The earthquake-induced slope deformation $\left(D_{a v e}\right)$ is the downward movement of the soil mass aligned along the inclination of the sliding surface. $D_{\text {avg }}$ was computed by taking the dot product of the horizontal and vertical components of the observed deformations and a unit vector aligned along the average inclination of the base of the sliding surface. The base inclination angle was specified from the critical failure from the pseudo-static analyses. The parameters $a_{y}, a_{\max }, T_{d}$ and $T_{p}$ represent yield acceleration, maximum horizontal earthquake acceleration, fundamental period 
of earth dam, and predominant earthquake period, respectively. The parameters $M_{w}, a_{\max }$ and $T_{p}$ represent as characteristics of earthquake loading and the parameters $a_{y}$ and $T_{d}$ as geotechnical characteristics of earth dam were considered as most influential parameters. The yield acceleration $\left(a_{y}\right)$ was estimated from pseudo-static slope stability analysis (Kaynia et al. 2011). The threshold acceleration above which the sliding mass is mobilized downslope called yield acceleration. The $a_{y}$ was taken to be equal to the inertial acceleration that yields a factor of safety of one in a pseudostatic analysis of the slope. The fundamental period of earth dam was taken from the case history references, if available. Otherwise, is estimated as $T_{d}=4 H / V_{s}$ (Rathje and Bray, 1999); where $H$ is the height of the earth dam and $V_{s}$ is the shear wave velocity in the dam body.

Based on the analysis of gathered case histories and review of the previous studies (Saygili and Rathje 2008; Jafarian and Lashgari 2016) the parameters $M_{w}, a_{y} / a_{\max }$ and $T_{d} / T_{p}$ were selected as input parameters in the model development. Subsequently, $75 \%$ of the collected data was employed in learning stage, whereas $25 \%$ was employed in validation stage. A trial selection procedure was performed for dividing the data to be used in learning and validation stages such that the statistical parameters of both categories remain as close as possible (Masters 1993). In order to accurately assess the model performance, different sets of data for learning and validation stages were selected with approximately equal statistical parameters. Subsequently, based on the error parameters, the best models were chosen for sensitivity analysis and comparisons. The statistical characteristics of inputs parameters (i.e., $M_{w}, a_{y} / a_{\max }, T_{d} / T_{p}$ ) and output parameter (i.e., $D_{\text {ave }}$ ) for the learning and validation stages as well as the entire results are presented in Table 1. The detailed characteristics of database are presented in Table A1. 


\section{Model development}

In this research, two soft computing-based models (i.e., feed forward back-propagation (FFBP) and radial basis function (RBF) neural networks) are developed to predict slope deformations of earth dams due to earthquake shaking.

\subsection{FFBP model}

One substantial benefit of the feed forward back-propagation (FFBP) networks in comparison to the other types of nonlinear methods is that they are universal predictors that can forecast many kinds of models with a high level of precision (Javdanian et al. 2015b). Initial assumption about the form of the model is not needed in the development process of model. The model is defined by three layers network of connected processing nodes (i.e., artificial neurons) (Fig. 2a).

The correlation between the inputs $\left(x_{l}, \ldots, x_{i}\right)$ and the output $\left(y_{t}\right)$ has the mathematical form according to Eq. (1):

$$
y_{t}=w_{0}+\sum_{j=1}^{S} w_{j} h\left(w_{0 j}+\sum_{i=1}^{R} w_{i, j} x_{i}\right)+\varepsilon_{t}
$$

where, $w_{i, j}(i=0,1,2, \ldots, R, j=1,2, \ldots, S)$ and $w_{j}(j=0,1,2, \ldots, S)$ are connection weights (or model parameters); $R$ and $S$ are the number of input and hidden nodes, respectively; $\varepsilon_{t}$ is the model's residual at the time $t$; and $h$ is the transfer-function (e.g., tan-sigmoid and log-sigmoid). In fact, the feed forward based model (Eq. 1) carries out a nonlinear-functional capturing from the previous records to the future prediction $y_{t}$, as Eq. (2): 


$$
y_{t}=g\left(x_{1}, \ldots, x_{R}, W\right)+\varepsilon_{t}
$$

where, $g$ is a function based on the connection weights and network structure, and $W$ is a vector including all model parameters.

The structure of the best-developed FFBP-based model was produced with one hidden layer. Then, the input vector was linked to the hidden neurons using transfer function of tan-sigmoid and the hidden neurons layer was linked to the output layer with a linear function. Learning process was initiated by three hidden artificial neurons to obtain the optimum number of neurons and favorable accuracy (Schalkoff 1997). As a result, the model with best performance was built using 12 hidden artificial neurons. In addition, the number of epochs in which the learning and validation stages have the best outputs was obtained to be 400 . In order to find a more efficient learning procedure, the inputs and output parameters were standardized to have unity standard deviation and zero mean.

\subsection{RBF model}

The radial basis function $(\mathrm{RBF})$ network is commonly employed for approximation problem in multi-dimensional space (Jafarian et al. 2014). Broomhead and Lowe (1988) were pioneers in applying RBFs in design of neural networks. They showed that a nonlinear correlation could be developed by RBF based network and interpolation problems could be modeled. RBF networks are local artificial networks in comparison to the FFBP networks, which carry out global capturing. $\mathrm{RBF}$ network utilizes a single class of processing units, and any of these units is receptive to a 
local domain of the input vector (Demuth et al. 2014). As shown in Fig. 2b, the RBF network structure consists of three layers. Radially symmetric function is employed as activation functions of hidden nodes in the RBF network.

In spite of feed forward networks, the input layer values of RBF networks are forwarded to the hidden layer without multiplying by connection weight. Subsequently, the hidden layer units assess the spacing between an input vectors with the center of its radial basis function and generates an output value based on the space. Although, many radial basis functions have been used in hidden layer, Gaussian function is the most commonly utilized in various applications (Chen et al., 1991). The mathematical function of the hidden neurons characterized by the Gaussian function is represented in Eq. (3):

$$
\rho_{j}=\exp \left(-\frac{\left\|X-\delta_{j}\right\|^{2}}{2 \mu_{j}^{2}}\right), j=1,2, \ldots, N
$$

where, $\rho_{j}$ is the output of the $j^{\text {th }}$ node in hidden layer; $X$ is the input vector, $\left\|X-\delta_{j}\right\|$ is Euclidian distance, $\delta_{j}$ is center of the $j^{\text {th }}$ Gaussian function, $\mu_{j}$ is radius of the Gaussian function of the $j^{\text {th }}$ node, and $N$ is the number of nodes in hidden layer.

The neuron in the output layer generates a weighted sum by the output of hidden layer and the weights connecting the hidden layer to the output layer. The output value of neural network can be introduced as Eq. (4): 
$y_{k}=\sum_{j=1}^{N} \rho_{j} w_{j}+b_{0 k}$

where, $w_{j}$ is the connection weight of hidden neuron $j$, and $b_{0 k}$ is the bias for final (output) layer neuron.

In the present research, radial basis function ( $\mathrm{RBF}$ ) network was utilized to predict slope deformation of earth dams under earthquake loading. The best-selected RBF network has 3 neurons in the input layer, 14 neurons in the hidden layer, and 1 neuron in the output layer, respectively. A spread of radial basis of one (1) was appropriate in this study.

\subsection{Performance assessment}

Correlation coefficient, $\mathrm{R}$, mean absolute percentage of error (MAPE), root mean square error (RMSE), scatter index (SI), and Bias were utilized to assess accuracy of developed FFBP and RBF based models using Eqs. (5-9):

$$
\begin{aligned}
& R=\frac{\sum_{i=1}^{N}\left[X_{i-\text { measured }}-\bar{X}_{\text {measured }}\right]\left[X_{i-\text { predicted }}-\bar{X}_{\text {predicted }}\right]}{\sqrt{\sum_{i=1}^{N}\left[X_{i-\text { measured }}-\bar{X}_{\text {measured }}\right]^{2} \cdot \sum_{i=1}^{N}\left[X_{i-\text { predicted }}-\bar{X}_{\text {predicted }}\right]^{2}}} \\
& M A P E=\frac{1}{N}\left[\frac{\sum_{i=1}^{N}\left|X_{i-\text { predicted }}-X_{i-\text { measured }}\right|}{\sum_{i=1}^{N} X_{i-\text { measured }}} \times 100\right]
\end{aligned}
$$


$R M S E=\left[\frac{\sum_{i=1}^{N}\left[X_{i-\text { predicted }}-X_{i-\text { measured }}\right]^{2}}{N}\right]^{0.5}$

$S I=\frac{R M S E}{(1 / N) \sum_{i=1}^{N} X_{i-\text { measured }}}$

Bias $=\frac{1}{N} \sum_{i=1}^{N}\left[X_{i-\text { predicted }}-X_{i-\text { measured }}\right]$

where, $X_{i-m e a s u r e d}$ is the measured slope deformation (from case histories), $X_{\text {-predicted }}$ is the predicted slope deformation (output of developed model), $\bar{X}_{\text {measured }}$ is the mean of measured values of dam deformations, $\bar{X}_{\text {predicted }}$ is the mean of predicted values of dam deformations, and $N$ is the number of deformation results.

\section{Results and discussions}

This study covered several networks with different initial parameters. With respect to the calculated error parameters, the models with the highest accuracy were selected to predict the slope deformation of earth dams under earthquake loading. The accuracy of the developed feed forward back-propagation (FFBP) model and radial basis function (RBF) model were compared with the measured values and the predicted values of $D_{\text {ave }}$ and are shown in Figs. 3 and 4, respectively. Also, the histogram of the residuals (i.e., predicted values minus measured values) and normalized $D_{a v e}$ (i.e., the ratio of the measured $D_{a v e}$ values to the predicted $D_{\text {ave }}$ values) against predicted 
amounts of $D_{\text {ave }}$ for both FFBP- and RBF-based models in the learning and validation stages are also superimposed in these figures.

Results indicated that, the values of R, RMSE, MAPE, SI and Bias of the developed FFBP model for assessing seismic slope deformations of earth dams (Fig. 3) were 0.912, 2.492, 1.101, 0.645 and 0.173 in the learning stage and $0.887,2.824,1.275,0.897$ and 0.223 in the validation stage, respectively. These parameters for the developed RBF model (Fig. 4) were 0.801, 2.648, 1.369, 0.685 , and 0.471 in the learning stage and $0.725,3.107,1.683,0.987$, and 0.728 in the validation stage, respectively.

Table 2 provides the values of R, MAPE, RMSE, SI and Bias for FFBP and RBF models in the learning and validation stages as well as the entire results recorded from the behavior of earth dams under previous earthquakes. The FFBP model No. 1 and RBF model No. 1 are the most appropriate models to predict slope deformations of earth dams induced by earthquake shaking. The results (Table 2) indicate the reasonable accuracy of soft computing based models in estimating seismic deformation of earth dams. Moreover, the results suggest that FFBP offered a higher accuracy than $\mathrm{RBF}$ in estimation of deformations. Next, the performance of the developed FFBP-based model was investigated in different conditions and in comparison with available relationships for estimation of earthquake-induced slope deformation of earth dams.

\subsection{Sensitivity analysis}

A sensitivity analysis was conducted to investigate: 1) the effect of each parameter involved in slope deformation of earth dams due to earthquake loading; and 2) the extent of consistency 
between the proposed soft computing models (i.e., FFBP model No. 1 and RBF model No. 1) and the results of real cases under different conditions. To this end, the effect of variations in each input parameters (i.e., $M_{w}, a_{y} / a_{\max }$ and $T_{d} / T_{p}$ ) on the amount of seismic deformation of earth dams $\left(D_{\text {ave }}\right)$ was examined. Meanwhile, other parameters assumed constant values equal to their mean values in the data set (Table 1).

The variation of seismic slope deformation of earth dams predicted by FFBP-based model versus the yield acceleration ratio $\left(a_{y} / a_{\max }\right)$ and fundamental period ratio $\left(T_{d} / T_{p}\right)$ at different earthquake magnitudes are depicted in Figs. 5 and 6, respectively. These figures also show the real values of $D_{\text {ave }}$ in earth dams caused by previous earthquakes along with the best-fitted curve for the purpose of comparison. As shown in Figs. 5 and 6, an increase in $a_{y} / a_{\max }$ and $T_{d} / T_{p}$ led to lower earthquake induced slope deformation of earth dams $\left(D_{\text {ave }}\right)$. Moreover, greater earthquake magnitudes led to higher $D_{\text {ave }}$. In general, the comparison of $D_{\text {ave }}$ variations versus the most important parameters affecting the seismic deformation of earth dams with the results of real case histories demonstrated the appropriate performance of the developed FFBP model.

\section{Comparison with the available recommendations}

Fig. 7 illustrates the performance of the FFBP based model in comparison to the conventional relationships (Saygili and Rathje 2008; Jibson 2007; Ambraseys and Menu 1988; Hynes-Griffin and Franklin 1984; Makdisi and Seed 1978) for estimating the slope deformation of earth dams due to earthquake loading. The relationships for earthquake-induced deformations of soil slopes are based on analyses of ground motions records using the Newmark sliding block. Fig. 7 displays cumulative frequency of relative error for developed model and available equations (Table 3). The 
relative error was calculated using Eq. (10):

$$
R E=\frac{D_{\text {ave-p }}-D_{\text {ave-m }}}{D_{\text {ave-m }}} \times 100
$$

where, the $D_{\text {ave-p }}$ is the average slope deformation predicted by the proposed FFBP model and also available relationships and $D_{\text {ave-m }}$ is the recorded slope deformations under previous earthquake shaking.

The relative error of available equations was calculated for the ranges presented in column 3 of Table 3. The values of relative error versus the measured values of seismic deformations are also added to the Figs. 7(a-f). As shown in Fig. 7, the developed FFBP model offers a reasonable accuracy compared to the available recommendations for assessment of slope deformation of earth dams due to earthquake shaking.

The behavioral complexity of earth structures under earthquake loading has prevented the conventional equations from accurately reflecting all factors contributing to the level of slope deformation. Nevertheless, the conventional equations and models (Table 3) are still extensively adopted in practical problems of geotechnical earthquake engineering. The adoption of advanced computing methods can definitely be an effective step towards mitigation of uncertainty concerning the estimation of deformation in earth dams under earthquake shaking.

\section{Summary and conclusions}


Accurate prediction of earthquake-induced slope deformations of earth dams is an important prerequisite for safe design. Therefore, it is critical to make an accurate assessment of how dams behave under earthquake shaking. This study attempts to predict the extent of slope deformation of earth dams under earthquake loads. To this end, a large set of real deformations found in different types of earth dams during past earthquakes were collected and analyzed. Then, the most important parameters contributing to slope displacement were determined. Earthquake magnitude $\left(M_{w}\right)$, maximum horizontal earthquake acceleration $\left(a_{\max }\right)$, yield acceleration of earth dam slope $\left(a_{y}\right)$, predominant earthquake period $\left(T_{P}\right)$, and fundamental period of earth dam $\left(T_{d}\right)$ are considered as most important parameters controlling the extent of seismic deformations in earth dams. Two artificial intelligence based models (including radial basis function, RBF, and feed forward backpropagation, FFBP, networks) were developed for prediction of earthquake induced slope deformations of earth dams $\left(D_{\text {ave }}\right)$. Performance of these models is validated using some part of gathered case histories. The results demonstrate that neural models considering the $M_{w}, a_{\max }$ and $T_{P}$ as strong ground motions parameters and $a_{y}$ and $T_{d}$ as geotechnical parameters are able to estimate the seismic slope deformations of earth dams with reasonable accuracy.

Comparing the predicted amounts of slope deformations with the recorded field data during past earthquakes showed reasonable accuracy of the FFBP $(\mathrm{R}=0.906$, RMSE $=2.543$, MAPE=1.167, $\mathrm{SI}=0.690$, Bias $=0.186)$ and $\mathrm{RBF}(\mathrm{R}=0.782, \mathrm{RMSE}=2.814, \mathrm{MAPE}=1.471, \mathrm{SI}=0.764, \mathrm{Bias}=0.584)$ based models. The error parameters indicated that the developed FFBP-based model has higher accuracy than the RBF-based model in assessment of seismic slope dam deformations.

A sensitivity analysis was performed to assess the influence of each input parameter on the amount of earthquake-induced slope deformations of earth dams and to better realize the performance of the proposed FFBP model. The variations trends of predicted $D_{a v e}-a_{y} / a_{\max }$ and $D_{a v e}-T_{d} / T_{p}$ curves 
under different values of $M_{w}$ were compared to the real case studies (historical events). The comparison results demonstrates reasonable performance of the developed FFBP-based model in the prediction of seismic slope deformations under various conditions. Finally, the performance of the proposed FFBP model was compared with the available relationships for evaluation of $D_{\text {ave }}$. The results clearly indicate that the proposed FFBP-based model has a higher precision in comparison to the previous recommendations.

\section{References}

Abdel-Ghaffar AM, Scott RF (1979) Analysis of earth dam response to earthquakes. J Geotech Eng 105:13791404.

Adeli H, Panakkat A (2009) A probabilistic neural network for earthquake magnitude prediction. Neural networks 22(7):1018-1024.

Ambraseys NN, Menu JM (1988) Earthquake-induced ground displacements. Earthq Eng Struct D 16(7):9851006.

Arrau L, Ibarra I, Noguera G (1985) Performance of Cogoti dam under seismic loading. In: Concrete Face Rockfill Dams-Design, Construction and Performance, Barry Cooke J, and Sherard JL (Eds.) ASCE pp: 1-14.

Bardet JP, Davis CA (1996) Performance of San Fernando dams during 1994 Northridge earthquake. J Geotech Geoenviorn Eng 122:554-563.

Baziar MH, Jafarian Y (2007) Assessment of liquefaction triggering using strain energy concept and ANN model: capacity energy. Soil Dyn Earthq Eng 27(12):1056-1072.

Boulanger RW, Bray JD, Merry SM, Mejia LH (1995) Three-dimensional dynamic response analysis of Cogswell Dam. Can Geotech J 32:452-464.

Bray JD, Travasarou T (2007) Simplified procedure for estimating earthquake-induced deviatoric slope displacements. J Geotech Geoenviorn Eng 133(4):381-392.

Broomhead DS, Lowe D (1988). Multivariable functional interpolation and adaptive networks. Complex Syst 2(3):321-355.

Bui DT, Tuan TA, Hoang ND, Thanh NQ, Nguyen DB, Van Liem N, Pradhan B (2017) Spatial prediction of rainfall-induced landslides for the Lao Cai area (Vietnam) using a hybrid intelligent approach of least squares support vector machines inference model and artificial bee colony optimization. Landslides 14(2):447-458. 
Bui DT, Tuan TA, Klempe H, Pradhan B, Revhaug I (2016) Spatial prediction models for shallow landslide hazards: a comparative assessment of the efficacy of support vector machines, artificial neural networks, kernel logistic regression, and logistic model tree. Landslides 13(2):361-378.

Bureau G, Volpe RL, Roth WH, Udaka T (1985) Seismic analysis of concrete face Rockfill dams. In: Barry Cooke, J., Sherard, J.L. (Eds.), Concrete Face Rockfill Dams-Design, Construction and Performance, ASCE, pp. 479-508.

Chaney RC (1979) Earthquake induced deformation in earth dams. Proceedings, $2^{\text {nd }}$ U.S. National Conf on Earthquake Eng, pp. 633-642.

Chen S, Cowan CFN, Grant, PM (1991) Orthogonal least squares learning algorithm for radial basis function networks. IEEE Trans Neural Net 2(2):302-309.

Choggang S (1988) Some Experiences from damages of embankments during strong earthquakes China. Proceeding of the $2^{\text {nd }}$ International Conference on Case Histories in Geotechnical Earthquake Engineering, 1: 729-735.

De Alba PA, Seed HB, Retamal E, Seed RB (1988) Analyses of dam failures in 1985 Chilean earthquake. J Geotech Eng 114:1414-1434.

Demuth HB, Beale MH, De Jess O, Hagan MT (2014) Neural network design. Martin Hagan.

Earthquake Engineering Research Institute (EERI) (2001) Bhuj, India Republic Day January 26, Reconnaissance Report.

EERI, Earthquake Engineering Research Institute (2004). Preliminary observation on the Al Hoceima Morocco earthquake of 24 February, 2004. Special report. EERI, Oakland, CA, USA.

Elgamal AW, Scott RF, Succarieh MF (1990) La Villita dam response during five earthquakes including permanent deformation. J Geotech Eng 114:1443-1462.

Ghorbani A, Jafarian Y, Maghsoudi MS (2012) Estimating shear wave velocity of soil deposits using polynomial neural networks: Application to liquefaction. Comput Geosci 44:86-94.

Hanna AM, Ural D, Saygili G (2007) Neural network model for liquefaction potential in soil deposits using Turkey and Taiwan earthquake data. Soil Dyn Earthq Eng 27(6):521-540.

Harder Jr, LH (1991) Performance of earth dams during Loma Prieta earthquake. Proc 2nd Int Conf on Recent Advances in Geotechnical Earthquake Eng 2:1613-1629.

Hynes-Griffin ME, Franklin AG (1984) Rationalizing the seismic coefficient method. Misc. Paper GL-84-13. U.S. Army Waterway Experiment Station, Vicksburg, Miss.

Ishihara K (1996) Soil behavior in earthquake geotechnics. Oxford Science Publications, p. 350.

Ishihara K, Okusa S, Oyagi N, Ischuk A (1990b) Liquefaction-induced flow slide in the collapsible loess deposit in Soviet Tajik. Soil Found 30:73-89.

Ishihara K, Yasuda S, Yoshida Y (1990a) Liquefaction-induced flow failure of embankments and residual strength of silty sands. Soil Found 30:69-80. 
Iwashita T, Yasuda N, Nakamura A, Takeda O (1995) Dynamic analysis of rockfill dams considering frequency dependent characteristics of radiation damping ratio. Proc $1^{\text {st }}$ Int Conf on Earthquake Geotech Eng 1:511-516.

Jafarian Y, Haddad A, Javdanian H (2014) Predictive model for normalized shear modulus of cohesive soils. Acta Geodyn Geomater 11(1):89-100.

Jafarian Y, Javdanian H, Haddad A (2018a) Strain-dependent dynamic properties of Bushehr siliceous-carbonate sand: experimental and comparative study. Soil Dyn Earthq Eng 107:339-349.

Jafarian Y, Javdanian H, Haddad A (2018b) Dynamic properties of calcareous and siliceous sands under isotropic and anisotropic stress conditions. Soils Found 58:172-184.

Jafarian Y, Lashgari A (2016) Simplified procedure for coupled seismic sliding movement of slopes using displacement-based critical acceleration. Int J Geomech 16(4):04015101.

Jafarian Y, Lashgari A (2017) Seismic sliding analysis of sandy slopes subjected to pore-water pressure buildup. Int J Geomech 17(11):04017106.

Javdanian H (2017a) Evaluation of soil liquefaction potential using energy approach: experimental and statistical investigation. Bull Eng Geol Environ, doi: 10.1007/s10064-017-1201-6.

Javdanian H (2017b) Assessment of shear stiffness ratio of cohesionless soils using neural modeling. Model Earth Syst Environ 3(3):1045-1053.

Javdanian H (2017c) The effect of geopolymerization on the unconfined compressive strength of stabilized finegrained soils. Int J Eng Trans B Appl 30(11):1673-1680.

Javdanian H, Haddad A, Jafarian A (2015a) Evaluation of dynamic behavior of fine-grained soils using group method of data handling, Transp Infrastruct Eng 1(3):77-92.

Javdanian H, Haddad A, Mehrzad B (2012) Experimental and numerical investigation of the bearing capacity of adjacent footings on reinforced soil. Electronic J Geotech Eng 17(R):2597-2617.

Javdanian H, Jafarian Y (2018). Dynamic shear stiffness and damping ratio of marine calcareous and siliceous sands. Geo-Mar Lett 38(4):315-322.

Javdanian H, Jafarian Y, Haddad A (2015b) Predicting damping ratio of fine-grained soils using soft computing methodology. Arab J Geosci 8(6):3959-3969.

Javdanian H, Lee S (2018) Evaluating unconfined compressive strength of cohesive soils stabilized with geopolymer: a computational intelligence approach. Eng Comput, doi: 10.1007/s00366-018-0592-8.

Javdanian H, Zarif Sanayei HR, Shakarami L (2018a) A regression-based approach to predict crest settlement of embankment dams under earthquake shaking. Sci Iran, doi: 10.24200/sci.2018.50483.1716.

Javdanian H, Shakarami L, Zarif Sanayei HR (2018b) Modeling seismic settlement of earth dams due to earthquake loading. International Conference on New Findings of Civil, Architectural and Iran Building Industry, 5 July, Tehran, Iran.

Javdanian H, Mirkamali O (2016). Estimation of liquefaction induced lateral deformations using adaptive neurofuzzy inference system. $4^{\text {th }}$ International Congress on Civil Engineering, Architecture \& Urban Development, 27 December, Tehran, Iran. 
Jibson RW (2007). Regression models for estimating coseismic landslide displacement. Eng Geol 91:209-218.

Kalantar B, Pradhan B, Naghibi SA, Motevalli A, Mansor S (2018) Assessment of the effects of training data selection on the landslide susceptibility mapping: a comparison between support vector machine (SVM), logistic regression (LR) and artificial neural networks (ANN). Geomat Nat Haz Risk 9(1):49-69.

Kaynia AM, Skurtveit E, Saygili G (2011) Real-time mapping of earthquake-induced landslides. Bull Earthquake Eng 9(4):955-973.

Kramer SL, Smith MW (1997) Modified Newmark model for seismic displacements of compliant slopes. J Geotech Geoenviorn Eng 123(7):635-644.

Krinitzsky EL, Hynes ME (2002) The Bhuj, India, earthquake: Lessons learned for earthquake safety of dams on alluvium. Eng Geol 66:163-196.

Krinitzsky EL, Hynes ME (2002) The Bhuj, India, earthquake: lessons learned for earthquake safety of dams on alluvium. Eng Geol 66:163-196.

Lingyao L, Kueifen L, Dongping B (1980) Earthquake damage of Baihe earth dam and liquefaction characteristics of sand and gravel materials. Proc $7^{\text {th }}$ World Conf on Earthquake Eng, Istanbul 3:171-178.

Makdisi FI, Seed HB (1978) Simplified procedure for estimating dam and embankment earthquake-induced deformations. J Geotech Eng 104(7):849-867.

Masters T (1993) Practical neural network recipes in C++. Academic press, San Diego.

Matsumoto M, Nakamura A, Sasaki T, Iwashita T (1996) Effects on Dams. Soils and Foundations (Special issue on Hyogoken Nambu Earthquake), pp. 273-281.

Matsuo O (2000) Report on the Western Tottori Prefecture earthquake of October 6. 33 $3^{\text {rd }}$ Tech Rep of US-Japan Natural Resources Development Program, Japan.

Meehan CL, Vahedifard F (2013) Evaluation of simplified methods for predicting earthquake-induced slope displacements in earth dams and embankments. Eng Geol 152(1):180-193.

Miller EA, Roycroft GA (2004a) Seismic Performance and Deformation of Leeves: Four case studies. J Geotech Geoenviron Eng 130:344-354.

Miller EA, Roycroft GA (2004b) Compaction grouting test program for liquefaction control. J Geotech Geoenviron Eng 130:355-361.

Mishima S, Kimura H (1970) Characteristics of landslides and embankment failures during the Tokachioki earthquake. Soil Found 10:39-51.

Miura K, Yoshida N, Wakamatsu K (1995) Damage to fill embankment during the 1993 Kushirooki earthquake. Proc $1^{\text {st }}$ Int Conf on Earthquake Geotech Eng 2:1057-1062.

Nagayama I, Yamaguchi Y, Sasaki T, Nakamura A, Kawasaki H, Hirayama D (2004) Damage to dams due to three large earthquake occurred in 2003, in Japan. $36^{\text {th }}$ Joint Meeting, Panel on Wind \& Seismic Effects, USJapan Natural Resources Development Program, Japan.

Najafzadeh M, Barani GA, Kermani MRH (2013) GMDH based back propagation algorithm to predict abutment scour in cohesive soils. Ocean Eng 59:100-106. 
Najafzadeh M, Lim SY (2015) Application of improved neuro-fuzzy GMDH to predict scour depth at sluice gates. Earth Sci Inform 8(1):187-196.

Newmark NM (1965) Effects of earthquakes on dams and embankments. Geotechnique 15(2):139-160.

Nicholas S (1995) Geotechnical Reconnaissance of the effect of the January 17, 1995, Hyogoken Nanbu earthquake, Japan. Report 95/01, EERC, University of California, Berkeley, CA, USA.

Okamura M (2003) Damage to river dikes. Quick report on the September 26, 2003 Tokachi-Oki Earthquake, Japan, National Institute of Standards \& Technology.

Okusa S, Anma S (1980) Slope failures and tailings dam damage in the 1978 Izu-Ohshima-Kinkai earthquake. Eng Geol 16:195-224.

Olson SM (2001) Liquefaction analysis of level and sloping ground using field case histories and penetration resistance. PhD Dissertation, University of Illinois, Urbana-Champaign.

Ozkan MY, Erdik M, Tuncer MA, Yilmaz C (1996) An evaluation of Surgu dam response during 5 May 1986 earthquake. Soil Dyn Earthq Eng 15:1-10.

Ozkan MY, Ozyazicioglu M, Aksar UD (2006) An evaluation of Güldürcek dam response during 6 June 2000 Orta earthquake. Soil Dyn Earthq Eng 26:405-419.

Ozutsumi O, Sawada S, Iai S, Takeshima Y, Sugiyama W, Shimazu T (2002) Effective stress analysis of liquefaction-induced deformation in river dikes. Soil Dyn Earthq Eng 22:1075-1082.

Pham BT, Pradhan B, Bui DT, Prakash I, Dholakia MB (2016) A comparative study of different machine learning methods for landslide susceptibility assessment: a case study of Uttarakhand area (India). Environ Modell Softw 84:240-250.

Pradhan B, Lee S (2010a) Delineation of landslide hazard areas on Penang Island, Malaysia, by using frequency ratio, logistic regression, and artificial neural network models. Environ Earth Sci 60(5):1037-1054.

Pradhan, B, Lee S (2010b) Regional landslide susceptibility analysis using back-propagation neural network model at Cameron Highland, Malaysia. Landslides, 7(1):13-30.

Prevost JH, Abdel-Ghaffar AM, Lacy SJ (1985) Nonlinear dynamic analyses of an earth dam. J Geotech Eng 111(7):882-897.

Rai DC, Murty CVR (2003) Reconnaissance report on North Andaman (Diglipur) earthquake of 14 September 2002. Department of Science and Technology, New Delhi.

Rampello S, Cascone E, Grosso N (2009) Evaluation of the seismic response of a homogeneous earth dam. Soil Dyn Earthq Eng 29(5):782-798.

Rathje EM, Bray JD (1999) An examination of simplified earthquake-induced displacement procedures for earth structures. Can Geotech J 36(1):72-87.

Rathje EM, Bray JD (2000) Nonlinear coupled seismic sliding analysis of earth structures. Journal of Geotechnical and Geoenvironmental Engineering 126 (11), 1002-1014.

Resendiz D, Romo MP, Moreno E (1982) El Infiernillo and La Villita dams: Seismic behavior. J Geotech Eng 108:109-131. 
Sakamoto S, Yoshida H, Yamaguchi Y, Satoh H, Iwashita T, Matsumoto N (2002) Numerical simulation of sliding of an earth dam during the 1985 Kobe earthquake. $3^{\text {rd }}$ US-Japan Workshop on Advanced Research on Earthquake Eng for Dams.

Sarma SK (1975) Seismic stability of earth dams and embankments. Geotechnique 25(4):743-761.

Sasaki Y, Tamura K, Yamamoto M, Ohbayashi J (1995) Soil improvement work for river embankment damaged by the 1993 Kushiro-Oki earthquake. Proc 1 ${ }^{\text {st }}$ Int Conf on Earthquake Geotech Eng, pp. 43-48.

Saygili, G., Rathje, E.M., 2008. Empirical predictive, models for earthquake-induced sliding displacements of slopes. J Geotech Geoenviorn Eng 134(6):790-803.

Schalkoff RJ (1997) Artificial neural networks. McGraw-Hill Higher Education.

Seed HB, Lee KL, Idriss IM, Makdisi FI (1975) The slides in the San Fernando dams during the earthquake of February 9, 1971. J Geotech Geoenviron Eng 101:651-688.

Seed HB, Makdisi IF, De Alba P (1978) Performance of earthen dams during earthquakes. J Geotech Eng 104:967-994.

Singh R, Roy D, Jain SK (2001) Analysis of earth dams affected by the 2001 Bhuj Earthquake. Eng Geol 80:282291.

Siyahi B, Arslan H (2008) Earthquake induced deformation of earth dams. Bull Eng Geol Environ 67(3):397403.

Strenk PM, Wartman J (2011). Uncertainty in seismic slope deformation model predictions. Eng Geol 122(12):61-72.

Tani S (1995) Consideration of fill dam behavior during the 1993 Kushiro-Oki Earthquake and the 1993 Hokkaido-Nensei-Oki earthquake. Proc $1^{\text {st }}$ Int Conf on Earthquake Geotech Eng 1:37-42.

Yan L (1991) Seismic deformation analysis of earth dams: a simplified method. Rep. SML 91-01, California Institute of Technology.

Yasuda N, Kondo M, Sano T, Yoshioka H, Yamaguchi Y, Sasaki T, Tomita M (2005) Effect of the mid Niigata prefecture earthquake in 2004 on dams. 37th Joint Meeting, Panel on Wind \& Seismic Effects, US Japan Natural Resources Development Program, Tech. Rep., pp. 1-16.

Yegian MK, Ghahraman VG, Harutinunyan RN (1994) Liquefaction and embankment failure case histories, 1988 Armenia earthquake. J Geotech Eng 120:581-596.

Yegian MK, Marciano EA, Ghahraman VG (1991) Earthquake-induced permanent deformations: probabilistic approach. J Geotech Eng 117(1):35-50. 


\section{List of Tables}

Table 1. Statistical analysis of inputs and output variables.

Table 2. Precision of the developed $D_{\text {ave }}$ models.

Table 3. Relationships for estimation of earth dam deformations under earthquake shaking.

Table A1. Summary of data set used to develop FFBP and RBF based models. 


\section{List of Figures}

Fig. 1. Histogram of frequency distribution of inputs and output parameters, a) earthquake magnitude, b) yield acceleration ratio, c) fundamental period ratio, and d) slope deformation.

Fig. 2. Structure of a) a feed-forward neural network, and b) radial basis function neural network.

Fig. 3. Measured vs. FFBP-based predicted values of $D_{\text {ave }}$, the values of residuals and normalized $D_{\text {ave }}$ are also added on the plot.

Fig. 4. Measured vs. RBF-based predicted values of $D_{a v e}$, the values of residuals and normalized $D_{a v e}$ are also added on the plot.

Fig. 5. Variations of the predicted $D_{a v e}-a_{y} / a_{\max }$ curves at different levels of $M_{w}$, the measured data with their best-fitted curves are superimposed on the plot.

Fig. 6. a) Comparison between the predicted and measured $D_{a v e}-T_{d} / T_{p}$ curves at different levels of $M_{w}$, and b) close-up view for $D_{a v e}<15 \mathrm{~m}$ and $T_{d} / T_{p}<10$.

Fig. 7. Distribution of cumulative frequency of relative error, a) This study (FFBP-based model), b) Sygili and Rathje (2008), c) Jibson (2007), d) Ambraseys and Menu (1988), e) Hynes-Griffin and Franklin (1984), and f) Makdisi and Seed (1978). 